\title{
Editorial
}

Ocular Oncology

and Pathology
Ocul Oncol Pathol 2019;5:205-209

DOI: $10.1159 / 000493486$
Received: July 10, 2018

Accepted after revision: September 5, 2018

Published online: November 29, 2018

\section{Epidemiology of Eyelid Malignancies in Indian Asians: The Importance of Being Earnest}

\author{
Bhupendra C.K. Patel \\ Division of Facial Cosmetic and Reconstructive Surgery, Moran Eye Center, University of Utah, \\ Salt Lake City, UT, USA
}

India, with a population of 1.35 billion, nearly $20 \%$ of the world's population, is establishing itself as an economic and intellectual powerhouse, not unlike China. The once yawning differences between developed and developing countries continue to shrink. Yet, accurate epidemiological data on some cancers, like malignant eyelid tumors, have never been obtained on a national level in India, unlike in many other (developed and developing) countries. Indeed, the first reports on malignant eyelid tumors were only published as recently as 1996, albeit small institution-based reports. Kaliki et al. [1] from Hyderabad, India, have gone some way in rectifying this deficiency: they have compiled an important analysis of 536 malignant eyelid tumors seen at their institution over a 22 -year period. Histopathology-proven diagnoses of these patients included sebaceous gland carcinoma (SGC; $n=285,53 \%$ ), basal cell carcinoma (BCC; $n=128,24 \%$ ), squamous cell carcinoma (SCC; $n=99,18 \%$ ), and miscellaneous tumors $(n=24,4 \%)$. The young oculoplastic resident or fellow would do well to scrutinize this paper carefully and be asked which of these statements is true. SGCs have a higher incidence in Asian Indians (hereafter referred to as Indians) than in Caucasians. SGC is much more common (higher incidence) than basal cell carci- noma in Indians (or twice as common, as they found). The commonest eyelid malignancy in Indians is SGC. In Indians, SGC is three times more common than SCC. BCC is more common in females across all age groups, with a male to female ratio of 1:1.5. Of course, none of these statements is necessarily true, based upon the findings of this study.

Epidemiology and epidemiological studies are infrequently presented or discussed in the oculoplastic surgery literature. Incidence (the number of newly diagnosed cases over a given period of time, usually 1 year), distribution, and prevalence (number of existing cases during a particular period of time) of a disease are important key concepts in epidemiology. Medical history is replete with examples of the importance of the incidence and distribution of disease.

Sir John Snow exemplified the importance of epidemiology in 1854 when he established the cause of the cholera epidemic in London by carefully studying the distribution of cases and showed that the cause of cholera was water and not "miasma" and contamination from sewers as had been popularly supposed [2]. He defined the incidence of cholera in two groups of populations, each supplied by a different source of water. Having identified the

\section{KARGER}

(C) 2018 S. Karger AG, Basel

E-Mail karger@karger.com

www.karger.com/oop
Prof. Bhupendra C.K. Patel, MD, FRCS 
incidence, he intervened to show that causality could be established. It is ironic that he died in 1858 with the miasma theory of cholera still prevalent. Snow's final vindication came in 1884, when the German microbiologist Robert Koch isolated and cultured the cholera bacillus Vibrio cholerae. For his persistent efforts to determine how cholera was spread and for the statistical and mapping methods he initiated, John Snow is widely considered to be the father of modern epidemiology [3]. Florence Nightingale, while volunteering as a nurse at the Middlesex Hospital in London during the same cholera outbreak of 1854 had become convinced that the socalled heroic medicine of the day, which was based on infusions of arsenic, mercury, opiates, and bleeding, hastened the deaths of many more patients than it saved. Her work with the injured in the Crimean war (1854-1856) has been recognized as having contributed significantly to epidemiology in spite of her having been a veritable gadfly to British parliamentarians of the day. In her journals she wrote, "all sciences of observations depend upon statistical methods - without these, are blind empiricism. Make your facts comparable before deducing causes. Incomplete, pell-mell observations arranged so as to support theory; insufficient number of observations; this is what one sees" [4].

To see confounding used deliberately to confuse in epidemiology, one only has to look at the Radium Girls in the 1920s: they were female factory workers who suffered from radiation poisoning from painting watch dials with self-luminous paint [5]. Basic epidemiological studies quickly established that radiation poisoning was the cause of the effects of this poisoning, namely, anemia, bone fractures, and necrosis of the jaw. Doctors, dentists and researchers did not cover themselves with glory on this occasion as they used the confounding factor of syphilis (which was prevalent at the time) to blame as being the cause of these problems.

With impressive advances in the health care systems in developing countries, many with world-class medical institutions, emphasis should no longer be only on diagnosis and treatment of common ailments. Properly performed epidemiological studies will be important for local populations and for international comparisons. Cancer registries, which are now established in many countries, organize systematic collection of cancer data, store the data, and allow an analysis of subjects with cancer. It is important to recognize that there are two main types of cancer registries: population-based cancer registries (PBCRs) and hospital-based cancer registries (HBCRs). As PBCRs collect data on, in theory, all new cases of cancer occurring in a particular population, this information gives an accurate idea of the burden of cancer, allows etiology studies as well as determination of changes in cancer rates and effectiveness of any treatments or preventative measures taken. These are supposed to be the most robust forms of registries [6]. However, even in the most advanced countries, the information is only as good as the data entered.

The Surveillance, Epidemiology, and End Results (SEER) Program run by the National Institute of Health began collection of data (on cancer incidence and survival) in 1973 from five states and two metropolitan areas (Detroit and San Francisco). Even with gradual expansion, the program still only covers 13 states, three Native Indian areas and four cities amounting to $34.6 \%$ of the US population. This is a robust program that collects data on patient demographics, primary tumor site, tumor morphology and stage at diagnosis, first course of treatment, and follow-up data (https://seer.cancer.gov). The International Cancer Control Partnership (ICCP) is a remarkable organization that allows cooperation with cancer control planning efforts around the world (https://www. iccp-portal.org/map).

The United Kingdom has a comprehensive system for registration of new cases of cancer through the National Cancer Registration and Analysis Service with registries in England, Scotland, Wales, and Northern Ireland. Using the English registry, Wawrzynski et al. [7] found that over a 15-year period (2000-2014), there was an increase in the age-standardized rate of eyelid SCC from 0.55 per 100,000 people in the period between 2000 and 2002 to 0.69 per 100,000 people in the period between 2012 and 2014 , an increase of approximately $2 \%$ per year. The mean age-standardized incidence rate of SCC during the study period was 0.63 cases per 100,000 population per year. They also found that the relative risk of eyelid SCC in men compared with women was 1.9. In a similar study over 11 years (2000-2010), Saleh et al. [8] found that unlike SCC, no major change in the age-standardized incidence of BCC was observed during the period between 2000 and 2010 in England. Overall, the age-standardized incidence of BCCs during the period between 2008 and 2010 was similar for males and females ( 4.51 per 100,000 and 4.53 per 100,000 , respectively). These were both excellent studies. Thus, establishing such baselines is obviously important for specific populations. However, the authors found that the proportion of all BCC cases in the registry with unrecorded anatomical sites rose from $6 \%$ in 2000 to $52 \%$ in 2010 ! No such information was provided in the SCC study, but one must assume that the 
numbers would be similar in the same population and reporting providers. So even in the most powerful registries, there are inherent flaws, sometime substantial. In these two papers from England, the actual incidence of BCCs and SCCs must obviously be higher than the figures quoted as in nearly half the cases reported, the site was not accurately recorded. The problems in more recently established cancer registries may be more severe. This exemplifies the old dictum that data are only as good as the accuracy of their collection.

In India, the National Cancer Registry Programme (NCRP) was commenced by the Indian Council of Medical Research (ICMR) with a network of cancer registries across the country in December 1981. Initially, there were six PBCRs in the NCRP's network: these covered only $3 \%$ of the country's population. The latest NCRP report (2013) provides data from 25 PBCRs covering $7.45 \%$ of the country's population which has recently increased to 29 PBCRs [9]. This is to be lauded. However, medical systems face different financial and manpower challenges: a review of the NCRP website shows excellent reports on the limited coverage of data collection for major cancers such as lung and breast cancers, but not for more specific cancers such as eyelid cancers. It is here that experienced groups such as the one in the L V Prasad Eye Institute can aid in database extension and specific data collection. With modern technology and mobile telephone penetration in India set to rise from the current 65 to $90 \%$ by 2020 , it should be possible to design electronic entry of new cancers and follow-up data collection from even the remotest of locations.

The concepts of chance, bias and confounding need to be understood by modern physicians if they are to carry out reliable epidemiological studies. The authors [1] recognize that referral bias to their tertiary care referral institution may play a role in the observed difference of eyelid tumor proportions. The referral of BCCs would be much lower compared to other tumors since these tumors may have been more easily managed by referring physicians. In their study, the history of prior intervention was highest for miscellaneous tumors (67\%), SCC (42\%), and SGC (41\%) suggestive of difficulties in managing these cases compared to BCC (18\%). This introduces understandable bias in this study. An example of confounding was given above in the case of the Radium Girls.

Another potential error is to lump all studies from a geographic area together. To that end, table 1 in their paper lists data from studies carried out in Japan, China, Singapore, Taiwan, Thailand, Korea, Iran, India, and

Epidemiology of Eyelid Malignancies in Indian Asians
Pakistan, which are all said to be Asian countries. This is where confusion of a more practical kind is created. Genetically, only the Indian and Pakistani populations may be deemed to be similar. India has a different genetic makeup from most of the other 48 Asian countries, except, perhaps, Pakistan, Sri Lanka, and Bangladesh. Even the genomic pool of the northeastern region of India has been found to be different from the rest of the country but resembles that of the southeastern Asian region [10]. Therefore, it is more useful to distill the table down to studies only from India and Pakistan (Table 1). All of these are institution-based tertiary referral center studies and therefore show different percentages of the eyelid skin cancers, surely depending upon the level of referral from their surrounding base. Little accurate epidemiological analysis may be obtained from these relatively small hospital-based studies. However, the L V Prasad study is an important hospital-based epidemiological study, which at least establishes some basic proportions of eyelid cancers in a tertiary referral practice covering 22 years, even if the incidence cannot be established.

The authors (correctly) only included eyelid malignancies diagnosed with histopathology. However, it would have been helpful to know the total number of cases of possible eyelid malignancy excluded because of a lack of histopathology. A total of $10 \%$ would be vastly different from 50\%. It is also not stated if the same patients with a second eyelid malignancy were included, especially as the presence of one eyelid malignancy increases the chances of future eyelid malignancies.

The commonly believed proposal that the incidence of SGC is higher in Asian populations compared to Caucasians and that this could be related to genetics and racial predisposition for SGC in Asians [22] is rightly challenged in this paper with the observation that in a retrospective study of 1,349 cases from the United States-based population registry (from the SEER database), the incidence of SGC was 2.03 cases per $1,000,000$ population in Whites versus 1.07 cases per $1,000,000$ population in Asian/Pacific Islanders versus 0.48 per $1,000,000$ population in Blacks, suggestive of a lack of racial predilection of SGC. In Asians, SGC does account for a higher proportion of eyelid malignancies similar to this study, but this is not due to a higher incidence of SGC but to a relative lack of other malignant eyelid tumors [23]. This exemplifies the need for proper population-based studies to determine the incidence.

What was not discussed in this paper [1] (understandably) is the variation in skin types in the Indian subcontinent. What are the relative Fitzpatrick skin types in the 
Table 1. Studies only from India and Pakistan

\begin{tabular}{|c|c|c|c|c|c|c|c|}
\hline First author [ref.], year & Country & $\begin{array}{l}\text { Total number } \\
\text { of patients with } \\
\text { malignant eyelid } \\
\text { tumors }\end{array}$ & BCC, \% & SCC, $\%$ & SGC, $\%$ & $\begin{array}{l}\text { Miscella- } \\
\text { neous } \\
\text { tumors, \% }\end{array}$ & $\begin{array}{l}\text { Most com- } \\
\text { mon malig- } \\
\text { nant eyelid } \\
\text { tumor }\end{array}$ \\
\hline Sihota [11], 1996 & India & 178 & 30 & 30 & 33 & 7 & SGC \\
\hline Abdi [12], 1996 & India & 85 & 39 & 22 & 27 & 12 & $\mathrm{BCC}$ \\
\hline Kale [13], 2012 & India & 85 & 48 & 14 & 31 & 7 & BCC \\
\hline Hussain [14], 2013 & Pakistan & 222 & 59 & 32 & 7 & 3 & $\mathrm{BCC}$ \\
\hline Ramya [15], 2014 & India & 24 & 27 & 22 & 41 & 10 & SGC \\
\hline Krishnamurthy [16], 2014 & India & 19 & 26 & 21 & 32 & 21 & SGC \\
\hline Rathod [17], 2015 & India & 39 & 41 & 10 & 41 & 8 & BCC, SGC \\
\hline Karan [18], 2016 & India & 9 & 33 & 11 & 56 & 0 & SGC \\
\hline Mohan [19], 2017 & India & 41 & 15 & 22 & 24 & 39 & SGC \\
\hline Gupta [20], 2017 & India & 9 & 22 & 11 & 44 & 22 & SGC \\
\hline Jangir [21], 2017 & India & 17 & 29 & 24 & 47 & 0 & SGC \\
\hline Kaliki [1], 2018 & India & 536 & 18 & 24 & 53 & 4 & SGC \\
\hline
\end{tabular}

Indian subcontinent? I have observed the full gamut, from Fitzpatrick type 1 to type 6 in my travels across India, but I do not know of any source of the exact percentages of each group in the population. It may be asking too much to document the underlying Fitzpatrick skin type for each eyelid malignancy registered, but when one is not aware of the natural distribution of the skin types in this large population, it may become an important epidemiological point. Furthermore, as the use of skin bleaching creams in India, Africa and elsewhere increases, incidences of eyelid skin cancers may well increase even in the higher Fitzpatrick skin types.

One assumes sentinel node biopsies were not performed in this study group as that is only a recent development and still not widely practiced. The locoregional lymph node metastatic rates will, therefore, by necessity, be underestimated. One can only presume from the clinical photographs presented in the paper that many of the simple cancers would have been treated elsewhere. Epidemiological studies, such as this, may be used to promote the early detection of eyelid malignancies with quick-reference photographic diagnostic aids, easily dispersed via the internet with an apt slogan (India being famous for catchy Bollywood and political slogans)! Eyelid malignancies are, after all, eminently curable and would greatly improve the quality of life.

As socioeconomic conditions improve with fewer people marinating in poverty, there is time for recreation and indulgence (although it has been my depressing observation that this seems to be bypassing young Indian doctors today who seem to work all hours of the day). Increased exposure to ultraviolet light, changing diets, a more sedentary lifestyle, increased smoking, pollution, and other factors have all led to an increase in the incidence of many different types of cancer and may have a bearing on eyelid malignancies.

This editorial is not a criticism of the L V Prasad study. Indeed, it is to stimulate and encourage a proclivity for profound and accurate epidemiological studies based on the findings of this group's excellent study. The ophthalmic curriculum is already overly cluttered with ever-increasing subspecialties. But the modern oculoplastic surgeon would gain much from reading Rothman et al. [24], who describe epidemiology as the study of the distribution and determinants of disease, its frequency and occurrence. Determining associations and risk factors of diseases, and thereby causality, will allow countries to promulgate health policy with prevention and treatment. From the clinician's perspective, it is critical that the documentation and reporting process is as complete as possible (coding, anatomical site, histology, and so on) to ensure optimal data quality for registration of cases.

For the present, the following questions remain unanswered. What is the incidence of eyelid malignancy in the Asian Indian population? What is the commonest eyelid malignancy in the Asian Indian population? Is the true incidence of SGC greater in Indians than in other populations? Is there an increase in the incidence of basal cell carcinomas over the years as has been reported in a number of other countries? Does the use of sentinel node biopsies in particular cancers improve local population sur- 
vival? Even accepting that this is not a population-based epidemiological study and no inferences on true incidences may be made, this particular paper represents an excellent vignette of the study of eyelid cancers in an institution which can help in informing policy. Furthermore, with the help of young clinician scientist epidemiologists, it may well serve as a platform for future population-based epidemiological studies in India (and the Indian subcontinent) and help answer some of those questions.

\section{Disclosure Statement}

The authors have no financial disclosures or conflicts of interest to report.

\section{Funding Sources}

This study was supported in part by an Unrestricted Grant from Research to Prevent Blindness, Inc., New York, NY, to the Department of Ophthalmology and Visual Sciences, University of Utah.

\section{References}

1 Kaliki S, Bothra N, Bejjanki KM, Nayak A, Ramappa G, Mohamed A, et al. Malignant eyelid tumors in India: a study of 536 Asian Indian patients. Ocul Oncol Pathol. 2018, DOI: $10.1159 / 000491549$.

2 Snow J. On the Mode of Communication of Cholera. Edinb Med J. 1856 Jan;1(7):668-70.

3 Cerda L J, Valdivia C G. [John Snow, the cholera epidemic and the foundation of modern epidemiology]. Rev Chilena Infectol. 2007 Aug;24(4):331-4. Spanish.

4 Diamond M, Stone M. Nightingale on Quetelet II, the marginalia. J R Stat Soc [Ser A]. 1981;144:181-2.

5 Gunderman RB, Gonda AS. Radium girls. Radiology. 2015 Feb;274(2):314-8.

6 Jedy-Agba EE, Curado MP, Oga E, Samaila MO, Ezeome ER, Obiorah C, et al. The role of hospital-based cancer registries in low and middle income countries-The Nigerian Case Study. Cancer Epidemiol. 2012 Oct;36(5): 430-5.

7 Wawrzynski J, Tudge I, Fitzgerald E, Collin R, Desai P, Emeriewen K, et al. Report on the incidence of squamous cell carcinomas affecting the eyelids in England over a 15-year period (2000-2014). Br J Ophthalmol. 2018 Oct; 102(10):1358-1361.

8 Saleh GM, Desai P, Collin JR, Ives A, Jones T, Hussain B. Incidence of eyelid basal cell carcinoma in England: 2000-2010. Br J Ophthalmol. 2017 Feb;101(2):209-12.
9 Sharma S, Satyanarayana L, Asthana S, Shivalingesh KK, Goutham BS, Ramachandra $S$. Oral cancer statistics in India on the basis of first report of 29 population-based cancer registries. J Oral Maxillofac Pathol. 2018 JanApr;22(1):18-26.

10 Sharma JD, Kalit M, Nirmolia T, Saikia SP, Sharma A, Barman D. Cancer: scenario and relationship of different geographical areas of the globe with special reference to North EastIndia. Asian Pac J Cancer Prev. 2014;15(8): 3721-9.

11 Sihota R, Tandon K, Betharia SM, Arora R. Malignant eyelid tumors in an Indian population. Arch Ophthalmol. 1996 Jan;114(1):1089.

12 Abdi U, Tyagi N, Maheshwari V, Gogi R, Tyagi SP. Tumours of eyelid: a clinicopathologic study. J Indian Med Assoc. 1996 Nov;94(11): 405-9.

13 Kale SM, Patil SB, Khare N, Math M, Jain A, Jaiswal S. Clinicopathological analysis of eyelid malignancies - A review of 85 cases. Indian J Plast Surg. 2012 Jan;45(1):22-8.

14 Hussain I, Khan FM, Alam M, Khan BS. Clinicopathological analysis of malignant eyelid tumours in north-west Pakistan. J Pak Med Assoc. 2013 Jan;63(1):25-7.

15 Ramya BS, Dayananda SB, Chinmayee JT, Raghupathi AR. Tumours of the eyelid-A histopathological study of 86 cases in a tertiary hospital. Int J Sci Res Pub. 2014;4:1-5.

16 Krishnamurthy $H$, Tanushree V, Venkategowda HT, Archana S, Mobin G, Archana S, et al. Profile of eyelid tumors at tertiary care institute in Karnataka: a 5-years survey. J Evolut Med Dent Sci. 2014;3(50):11818-32.
17 Rathod A, Modini P, Kavitha T, Samir B. A clinicopathological study of eyelid tumours and its management at a tertiary eye care centre of Southern India. MRIMS J Health Sciences. 2015;3:54-8.

18 Karan S, Nathani M, Khan T, Ireni S, Khader S. Clinicopathological study of eyelid tumors in Hyderabad - A review of 57 cases. J Med Appl Sci. 2016;6(2):72-6.

19 Mohan BP, Letha V. Profile of eye lid lesions over a decade: a histopathological study from a tertiary care center in South India. Int J Adv Med. 2017;4(5):1406-11.

20 Gupta P, Gupta RC, Khan L. Profile of eyelid malignancy in a Tertiary Health Care Center in North India. J Cancer Res Ther. 2017 JulSep;13(3):484-6.

21 Jangir MK, Kochar A, Khan NA, Jaju M. Profile of eyelid tumours: histopathological examination and relative frequency at tertiary centre in north-west Rajasthan. Delhi J Ophthalmol. 2017;28(2):30-5.

$22 \mathrm{Ni} \mathrm{C}$, Searl SS, Kuo PK, Chu FR, Chong CS, Albert DM. Sebaceous cell carcinomas of the ocular adnexa. Int Ophthalmol Clin. 1982; 22(1):23-61.

23 Dasgupta T, Wilson LD, Yu JB. A retrospective review of 1349 cases of sebaceous carcinoma. Cancer. 2009 Jan;115(1):158-65.

24 Rothman KJ, Greenland S, Lash TL. Modern epidemiology. Philadelphia: Lippincott Williams \& Wilkins; 2008 